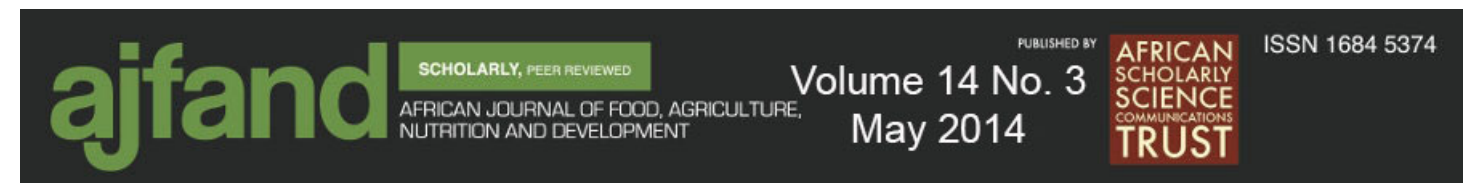

\title{
AFLATOXINS CONTAMINATION IN PROCESSED CASSAVA IN MALAWI AND ZAMBIA
}

Chiona $\mathrm{M}^{1}$, Ntawuruhunga $\mathrm{P}^{2}$, Benesi $\operatorname{IRM}^{3}$, Matumba $\mathrm{L}^{3}$ and CC Moyo ${ }^{2}$

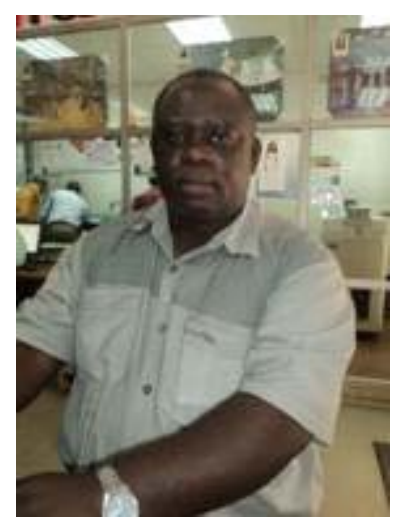

Martin Chiona

*Corresponding author email: martinchiona@yahoo.com

${ }^{1}$ Mansa Agricultural Research Station, P.O. Box 710129, Mansa, Zambia

${ }^{2}$ IITA Malawi, P.O. Box 30258, Lilongwe, Malawi 3

${ }^{3}$ Chitedze Agricultural Research Station, P.O. Box 158, Lilongwe, Malawi 


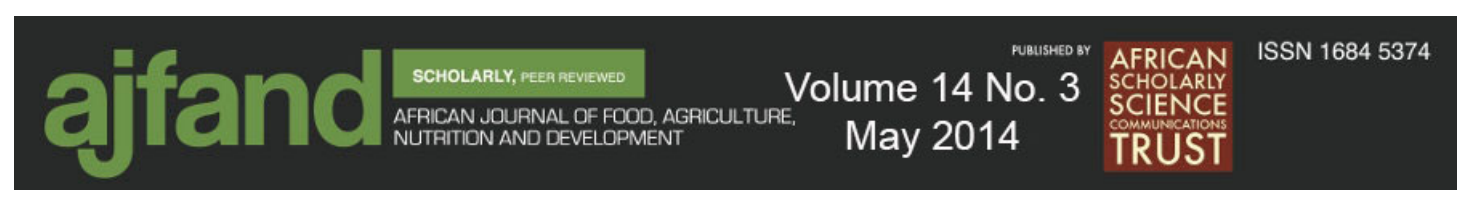

\section{ABSTRACT}

Strains of the Aspergillus fungi, especially A. flavus and A. parasiticus, primarily produce aflatoxins which are a major health concern to man and livestock because of their acute and chronic health effects. Aflatoxins pose the greatest risk to health in tropical Africa because of their widespread prevalence and high toxicity; carcinogenic (cause liver and esophageal cancer) effect, immune system suppressing and antinutritional contaminants in many food commodities and even cause death. Aflatoxins have also been reported to compromise vaccine efficacy in experimental animals. Due to the seriousness of aflatoxins, international agencies have restricted levels of aflatoxins to $20 \mathrm{ppb}$ in food materials as the maximum permissible level in the United States and $4 \mathrm{ppb}$ total aflatoxins and under $2 \mathrm{ppb}$ aflatoxin B1 in Europe. These regulations directed at minimizing human exposure to aflatoxins results in severe economic loss to producers, processors and marketers of the contaminated crop. A study was conducted in Malawi and Zambia to assess the level of fungal and mycotoxins' contamination in commonly processed cassava products. A total of 92 and 88 samples of processed cassava products comprising makaka, flour, kanyakaska, kadonoska, scrapes and grates were collected in the rainy season of 2008 and 2009 in Malawi, respectively. Further, 22 samples of processed cassava products comprising dried cassava chips and flour were collected in the rainy season of 2009 in Zambia. The samples were analyzed for fungal and aflatoxins B1, B2, G1 and G2 contamination using the Romer mini-column method and the VICAM AflaTest immunoaffinity fluorometric method. None of the samples in 2008 were contaminated with aflatoxins. Similar results were obtained in 2009 with almost all the samples in Malawi and Zambia having aflatoxin levels much lower $(\leq 2.0 \mu \mathrm{g} / \mathrm{kg}$ in Malawi and $<4.2 \mu \mathrm{g} / \mathrm{kg}$ in Zambia) than the Codex Alimentarius Commission (CAC) maximum permissible level of aflatoxins of $10.0 \mu \mathrm{g} / \mathrm{kg}$, implying that the cassava products analyzed were safe for human consumption. However, further studies are needed to cover a larger sample size over a period of a year to represent all seasons in the cassava producing and consuming areas and conclusively make certain the safety of these products for human consumption.

Key words: Cassava, consumption, aflatoxin, food, safety 


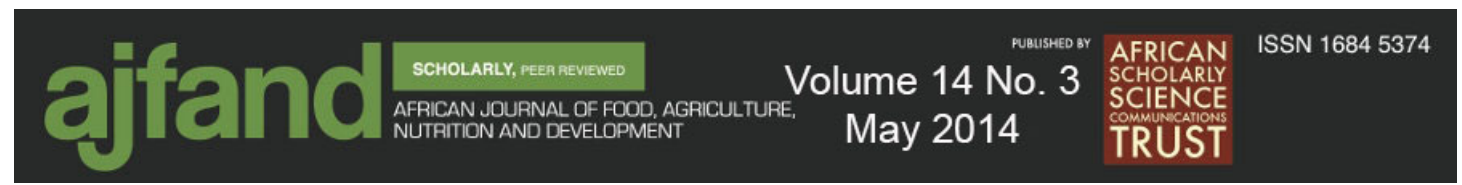

\section{INTRODUCTION}

Cassava (Manihot esculenta Crantz) is a major staple food crop across tropical subSaharan Africa [1]. In Malawi and Zambia it is the second most important staple (after maize) nourishing over 30\% of the population. Besides being an important food, cassava has huge potential for industrial application in the plywood, confectionery, feed and pharmaceutical sectors [2, 3, 4].

As cassava is highly perishable, it is often processed into dry forms such as kadonoska ${ }^{1}$, kanyakaska ${ }^{2}, m_{a k a k a^{3}}$, fermented and unfermented flour to increase shelf life. Kadonoska, kanyakaska and makaka are processed into flour for nsima ${ }^{4}$ (nshima in Zambia) or confectioneries or stored for later use. However, poor drying during processing or storage, especially during the rainy season, often results in contamination by fungi such as Aspergillus, Fusarium and Penicillium. This is because rain/drizzles may fall on the drying products and predispose them to mould growth as drying is often done in the open and unprotected areas.

Many of the Aspergillus fungi, especially A. flavus and A. parasiticus, produce aflatoxins which are a major health concern to man and livestock because of their acute and chronic health effects. Aflatoxins pose the greatest risk to health in tropical Africa because of their widespread prevalence and high toxicity [5] and have been known to be carcinogenic (cause liver and esophageal cancer), immune system suppressing [6, 7] and anti-nutritional contaminants in many food commodities [8] and even to cause death. In addition, they have been reported to compromise vaccine efficacy in experimental animals $[9,10]$. Aflatoxins' role in reduction of child growth and development has also been reported [11]. Since chronic diseases in developing countries are underreported, the actual health impacts of aflatoxins may be higher than what is known.

Studies in Uganda, Kenya, and Democratic Republic of Congo, Tanzania, Thailand, Brazil and Indonesia have shown that processed cassava can be contaminated with aflatoxins to various levels [3, 5, 12, 13, 14, 15]. However, in the Southern Africa region, there is little information on the level of aflatoxin contamination in processed cassava that would enable consumers to take precautionary measures against consumption of such products. The present paper reports on the results of a survey appraisal that was conducted in Malawi and Zambia to assess the aflatoxin situation of locally processed cassava products.

\footnotetext{
${ }^{1}$ Dried fermented cassava pulp molded into small balls with a depression at the center to facilitate drying

${ }^{2}$ Dried fermented cassava pulp broken into small pieces for ease of drying

${ }^{3}$ Dried cassava chips, usually unfermented

${ }^{4}$ Thick starchy porridge made from maize, cassava, or other starch flour
} 


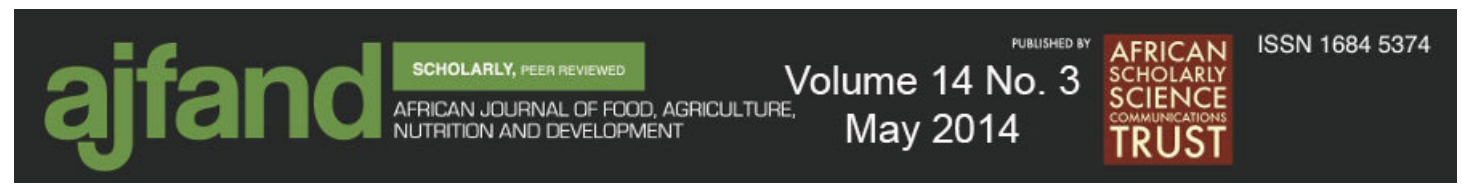

\section{MATERIALS AND METHODS}

The study was conducted during the rainy season (November to May) of 2008 and 2009 in Malawi and the rainy season of 2009 in Zambia. The rainy season was targeted because mould growth during processing or storage is a problem during this period due to high humidity [16].

In Malawi, samples of processed cassava products, each weighing $1 \mathrm{~kg}$, were randomly collected from households in main cassava growing districts of Mulanje, Chiradzulu (confectionery processing warehouse), Zomba and Mangochi in the southern region; Nkhotakota and Kasungu in the central region and Rumphi, Mzimba (Mzuzu market) and Nkhata Bay in the northern region. Some samples were collected purposefully from main processing units in Lilongwe and Blantyre. A total of 92 samples comprising makaka, kanyakaska, kadonoska, fermented and unfermented flour, scrapes and grates were collected in February 2008 and another 88 samples comprising makaka, fermented flours, kanyakaska and kadonoska were collected in March 2009. More samples (>80\%) were collected in Nkhata Bay and Nkhotakota because of the abundance of the processed products in the area.

The 2008 samples were analyzed for fungal and aflatoxins B1, B2, G1 and G2 contamination using the Romer mini-column method. Due to the lower sensitivity of this method (limit of detection of $2 \mu \mathrm{g} / \mathrm{kg}$ ) the samples that were collected in 2009 were analyzed using the VICAM AflaTest ${ }^{\circledR}$ immunoaffinity fluorometric method [17] (limit of detection of $1 \mu \mathrm{g} / \mathrm{kg}$ ) that quantifies total aflatoxin (B1+B2+G1+G2) concentrations using AflaTest ${ }^{\circledR}$ Fluorometer Series-4.

In Zambia, a total of 22 samples, 21 of dried chips and 1 of flour, each weighing $1 \mathrm{~kg}$, were collected in April 2009 from farmers and market places in Mansa and Mwense districts in Luapula province, Kasama and Luwingu districts in Northern province, Kabompo and Solwezi districts in Northwestern province, Kaoma and Lukulu districts in Western province and Ndola district in Copperbelt province. The districts were purposefully selected as they were potential areas for cassava production, processing and utilization. However, the collection of samples within each district targeted areas where processed cassava was likely to be found such as homes and market places. The samples collected were from the previous dry season's harvest hence were about a year old. Many farmers do not keep their processed cassava for that long hence the limited samples collected in Zambia. The samples were analyzed for total aflatoxins using the VICAM AflaTest ${ }^{\circledR}$ immunoaffinity fluorometric method [17].

\section{RESULTS}

None of the cassava samples collected in 2008 in Malawi were contaminated with aflatoxins B1, B2, G1 and G2 as the concentrations were less than $2 \mu \mathrm{g} / \mathrm{kg}$ (Table 1). According to the method used in the analysis (Romer mini-column) the limit of detection was $2 \mu \mathrm{g} / \mathrm{kg}$ and samples which tested less than this value were taken as 


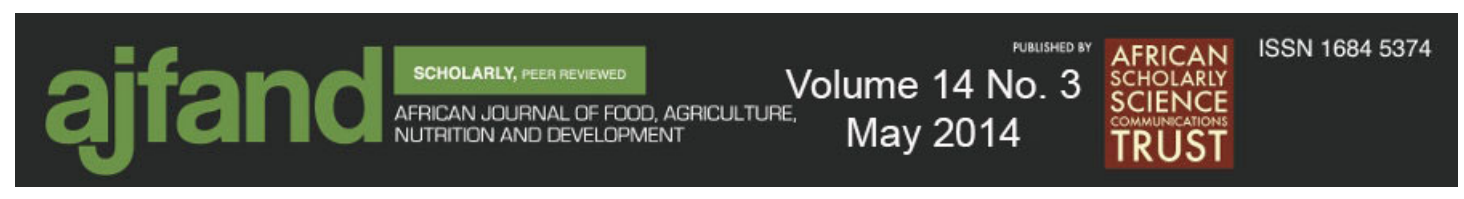

negative. The only contamination detected, however, was in the unfermented samples (scrapes, makaka and unfermented flour) but this was due to Microphomina phaseoli fungus and not aflatoxins B1, B2, G1 or G2. This indicates that the samples were free from aflatoxins contamination and hence fit for human consumption.

Similar results were obtained in 2009. Only 2 (2\%) of the 88 samples collected in Malawi were contaminated with aflatoxins but in both cases the concentration was $<2$ $\mu \mathrm{g} / \mathrm{kg}$ (Table 2). Similarly, in Zambia 2 (9.1\%) of the 22 samples collected were detected with aflatoxins, one with $4.2 \mu \mathrm{g} / \mathrm{kg}$ and the other with $16.0 \mu \mathrm{g} / \mathrm{kg}$ (Table 3).

\section{DISCUSSION}

In general, the levels of contamination in this study were much lower than the Codex Alimentarius Commission (CAC) maximum permissible level of aflatoxins of 10 $\mu \mathrm{g} / \mathrm{kg}$ in ready to eat foods [18] except for one sample from Zambia that had a higher level $(16.0 \mu \mathrm{g} / \mathrm{kg})$ than this. The results indicate that very little aflatoxin contamination takes place in processed cassava in the two countries which implies that farmers are consuming safe products free of aflatoxins. However, the absence of aflatoxins in mouldy samples suggests possible prevalence of other mycotoxins that were not tested in this study. Low aflatoxins incidences in cassava have also been reported elsewhere. In Tanzania, 18 samples of cassava products processed by smallholder farmers using sun drying and solid state fermentation showed no aflatoxins contamination [19]. Similar results were reported in Ghana in 2 samples of $k_{k o k o n t}^{5}[16]$. Also, a report on the assessment of cassava chips in Benin revealed no aflatoxins or fumonisin B1 contamination [20] and no aflatoxins contaminations were found in 14 samples of dark and moldy cassava in Mozambique and in 10 samples of cassava flour in Uganda [21]. Considering that surveys of other food matrices in Malawi have shown high concentrations of aflatoxins [22, 23, 24, 25, 26], the low aflatoxin contamination in the cassava products supports earlier conclusion that cassava does not provide a good substrate for aflatoxin production [27]. In contrast, in Uganda relatively high incidences (30\%) of aflatoxin contamination were reported even though the levels were low $(<4.5 \mu \mathrm{g} / \mathrm{kg})$ [3] while in the Philippines even higher incidences (100\%) and contamination (mean of $467.5 \mu \mathrm{g} / \mathrm{kg}$ ) in 142 samples of processed cassava products were reported [28] which was much higher than the $2.0 \%$ in Malawi and 9.1\% in Zambia, respectively, found in this study.

The results of this study are contrary to findings from other studies [5, 13, 28] despite the fact that only locally processed products of different sizes were sampled. All the makaka (chips) that were sampled were of large size and the sampling was done during the rainy period both in Malawi and Zambia. While comparing the safety of traditionally processed cassava chips with those processed using improved chipping machine in Uganda, higher aflatoxins levels in traditionally processed $(15 \mu \mathrm{g} / \mathrm{kg})$ than in improved chipping machine processed $(0.07 \mu \mathrm{g} / \mathrm{kg})$ cassava chips were reported [13]. The levels in traditionally processed chips were also higher than the normative

\footnotetext{
${ }^{5}$ Fermented dried cassava product
} 


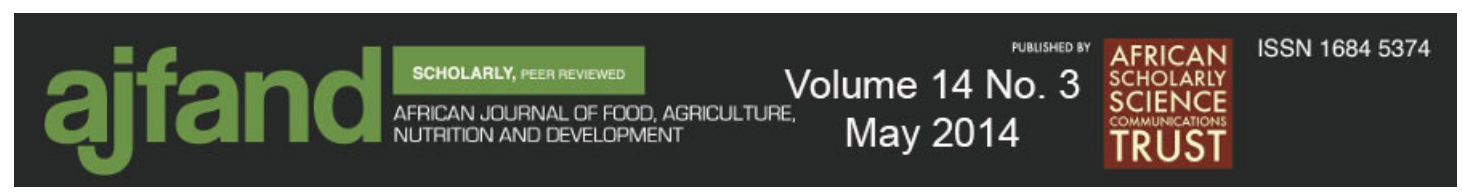

level of $10 \mu \mathrm{g} / \mathrm{kg}$ [28]. Another study [5] reported that levels of aflatoxin B1 varied from 0.3 to $4.4 \mu \mathrm{g} / \mathrm{kg}$ in cassava chips and flour and from 0.1 to $13.0 \mu \mathrm{g} / \mathrm{kg}$ in stored cassava samples, with relatively high levels of contamination in cassava stored for 4 months. This corroborated with another study in the same year [13] which reported that humidity, which is prerequisite for aflatoxin contamination, increases with an increase in chip size, insect damage and length of storage period. As high humidity is a pre-requisite for aflatoxin contamination, it is unlikely that there can be high contamination during the dry season (May to November) when the humidity is low and the drying is faster due to less cloudy conditions.

\section{CONCLUSION}

The study has shown that there is little aflatoxins contamination in the processed cassava products in Malawi and Zambia. This implies that the people are consuming safe cassava products free from aflatoxins' contamination. However, as the survey did not cover in detail all conditions that favour aflatoxin contamination, it could be also possible that other mycotoxins that were not tested may be prevalent. There is need, therefore, to conduct further intensive studies on other mycotoxins in cassava products being consumed in Malawi and Zambia. Meanwhile, it is recommended that farmers/consumers should ensure proper drying and storage of their cassava products to minimize mould growth and avoid consumption of mycotoxin contaminated products. 


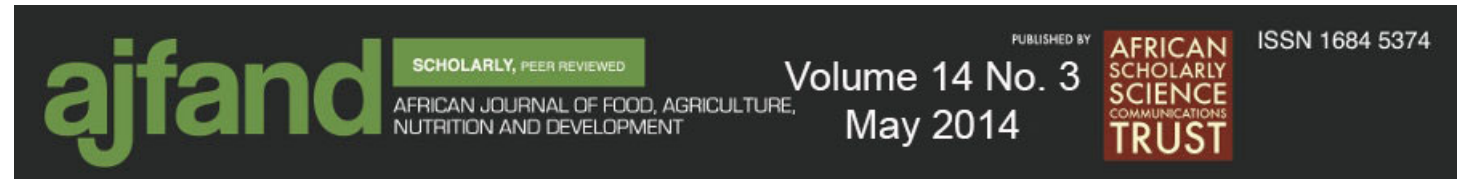

Table 1: Aflatoxins levels in processed cassava products collected in February/March 2008 in Malawi

\begin{tabular}{|c|c|c|c|}
\hline Type of sample & $\begin{array}{l}\text { Quality of } \\
\text { sample }\end{array}$ & $\begin{array}{l}\text { No. of } \\
\text { samples }\end{array}$ & $\begin{array}{l}\text { Aflatoxins } \\
\text { concentration } \\
(\mu \mathrm{g} / \mathrm{kg})\end{array}$ \\
\hline Heap fermented chips & Mould free & 15 & $<2$ \\
\hline Heap fermented chips & Moldy & 6 & $<2$ \\
\hline Kadonoska & Mould free & 2 & $<2$ \\
\hline Kanyakaska & Moldy & 1 & $<2$ \\
\hline Kanyakaska & Weeviled & 3 & $<2$ \\
\hline Kanyakaska & Mould free & 5 & $<2$ \\
\hline Kondowole & Mould free & 4 & $<2$ \\
\hline Kondowole & Moldy & 1 & $<2$ \\
\hline Makaka & Mould free & 7 & $<2$ \\
\hline Makaka & Moldy & 5 & $<2$ \\
\hline Makaka & Weeviled & 12 & $<2$ \\
\hline Scrapes & Mould free & 2 & $<2$ \\
\hline Scrapes & Moldy & 1 & $<2$ \\
\hline Unfermented flour & Mould free & 1 & $<2$ \\
\hline Unfermented flour & Moldy & 1 & $<2$ \\
\hline Total & & 66 & \\
\hline
\end{tabular}




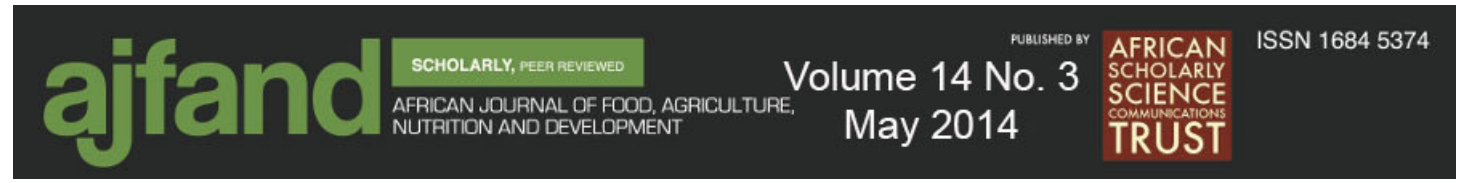

Table 2: Aflatoxins levels in processed cassava products collected in March 2009 in Malawi

\begin{tabular}{|c|c|c|c|c|c|}
\hline \multirow[b]{2}{*}{ District } & \multicolumn{5}{|c|}{ Number of samples collected and source } \\
\hline & Farmer & $\begin{array}{l}\text { Shop } \\
\text { /vendor }\end{array}$ & $\begin{array}{l}\text { Commercial } \\
\text { processor }\end{array}$ & Total & $\begin{array}{l}\text { Aflatoxin } \\
\text { content }(\mu \mathrm{g} / \mathrm{kg})\end{array}$ \\
\hline Nkhata Bay & 32 & 5 & 0 & 37 & $<1.0$ \\
\hline Nkhotakota & 28 & 8 & 0 & 29 & $<1.0$ \\
\hline Zomba & 1 & 1 & 2 & 4 & $<1.0$ \\
\hline Chiladzulu & 0 & 3 & 2 & 5 & $<1.0$ \\
\hline Mulanje & 0 & 2 & 0 & 2 & $<1.0$ \\
\hline Lilongwe & 0 & 0 & 2 & 2 & $<1.0$ \\
\hline Total & 61 & 19 & 6 & 79 & \\
\hline Nkhata Bay & 1 & 0 & 0 & 1 & $>1.0-2.0$ \\
\hline Nkhotakota & 0 & 1 & 0 & 1 & $>1.0-2.0$ \\
\hline Total & 1 & 1 & 0 & 2 & \\
\hline
\end{tabular}




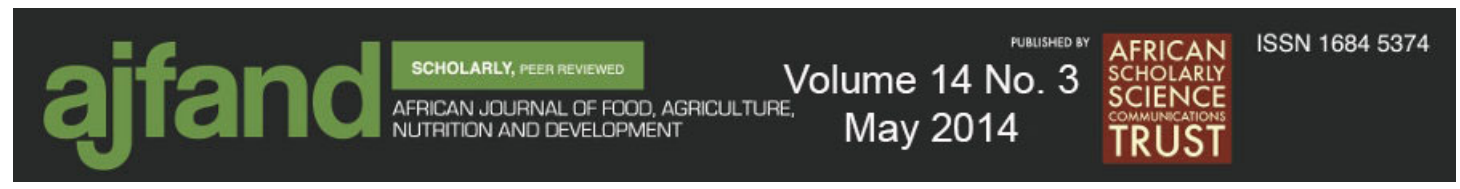

Table 3: Aflatoxins levels in processed cassava products collected in April 2009 in Zambia

\begin{tabular}{|c|c|c|c|c|}
\hline $\begin{array}{l}\text { Type of } \\
\text { Product }\end{array}$ & Source & Town & Village & $\begin{array}{l}\text { Aflatoxins } \\
\text { content }(\mu \mathrm{g} / \mathrm{kg})\end{array}$ \\
\hline Dried chips & Farmer & Mansa & Nyense & $<1.0$ \\
\hline Dried chips & Farmer & Mansa & Samba & $<1.0$ \\
\hline Dried chips & Farmer & Mansa & Matanda & $<1.0$ \\
\hline Dried chips & Farmer & Mamba & - & $<1.0$ \\
\hline Dried chips & Farmer & Kabompo & - & $<1.0$ \\
\hline Dried chips & Farmer & Kabompo & Kaivu & $<1.0$ \\
\hline Dried chips & Farmer & Lukulu & - & $<1.0$ \\
\hline Dried chips & Farmer & Mwense & Chipokotola & $<1.0$ \\
\hline Dried chips & Farmer & Mwense & - & $<1.0$ \\
\hline Dried chips & Farmer & Mwense & Chipokotola & $<1.0$ \\
\hline Dried chips & Farmer & Kaoma & Nginda & $<1.0$ \\
\hline Dried chips & Farmer & Kaoma & - & $<1.0$ \\
\hline Dried chips & Farmer & Kaoma & - & $<1.0$ \\
\hline Dried chips & Farmer & Solwezi & - & $<1.0$ \\
\hline Dried chips & Farmer & Isoka & - & $<1.0$ \\
\hline Dried chips & Farmer & Kasama & Dairy Scheme & $<1.0$ \\
\hline Dried chips & Farmer & Kasama & Nsando & \\
\hline Dried chips & Farmer & Mongu & - & $<1.0$ \\
\hline Dried chips & Farmer & Luwingu & Museya & $<1.0$ \\
\hline Flour & Farmer & Ndola & Masala Market & $<1.0$ \\
\hline Dried chips & Farmer & Kasama & Chibo & 4.20 \\
\hline Dried chips & Farmer & & Kajanga & 16.0 \\
\hline
\end{tabular}




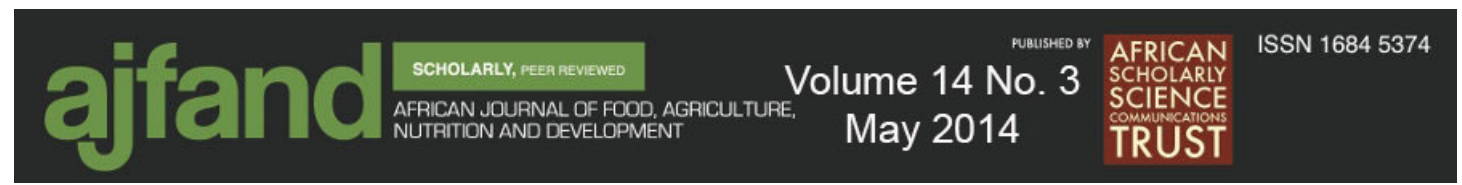

\section{REFERENCES}

1. FAO. FAOSTAT. (http://faostat.fao.org/). 2012. Accessed on $10^{\text {th }}$ December 2012.

2. Moyo CC, Mahungu NM, Sandifolo VS, Jumbo S, Mhone A and PT Mangirani Investigations into cassava stem storage and its effects on sprouting and growth. Proceedings of the $9^{\text {th }}$ ISTRC-AB Symposium, Kenya, 2004.

3. Kaaya AN and D Eboku Mould and Aflatoxin Contamination of Dried Cassava Chips in Eastern Uganda: Association with Traditional Processing and Storage Practices. Journal of Biological Science. 2010; 10: 718-729.

4. FAO. Cassava processing. FAO Plant Production and Protection Series No. 3, 1977.

5. Manjula K, Hell K, Fandohan P, Abass A and $\mathbf{R}$ Bandyopadhyay Aflatoxin and fumonisin contamination of cassava products and maize grain from markets in Tanzania and Republic of the Congo. Informa Healthcare. 2008.

6. Jiang Y, Jolly PE, Ellis WO, Wang JS, Phillips TD and JH Williams Aflatoxin B1 albumin adduct levels and cellular immune status in Ghanaians. International Journal of Immunology 2005; 17(6):807-814.

7. Turner PC, Sylla A, Gong YY, Diallo MS, Sutcliffe AE, Hall AJ and CP Wild Reduction in exposure to carcinogenic aflatoxins by postharvest intervention measures in West Africa: a community based intervention study. Lancet 2005; 365: 1950-1956.

8. Williams JH, Phillips TD, Jolly PE, Stiles JK, Jolly CM and D Aggarwal Human aflatoxicosis in developing countries: A review of toxicology, exposure, potential health consequences and interventions. American Journal of Clinical Nutrition 2004; 80: 1106-1122.

9. Cysewski SJ, Wood RL, Pier AC and AL Baetz Effects of aflatoxin on the development of acquired immunity to swine erysipelas. American Journal of Veterinary Research 1978; 39:445-448.

10. Batra P, Pruthi AK and JR Sadana Effect of aflatoxin B1 on the efficacy of turkey herpesvirus vaccine against Marek's disease. Research in Veterinary Science 1991; 51 (1):115-9. 
11. Gong YY, Hounsa A, Egal S, Turner PC, Sutcliffe AE, Hall AJ, Cardwell KF and CP Wild Post-weaning exposure to aflatoxin results in impaired child growth: A Longitudinal study in Benin, West Africa. Environmental Health Perspective 2004; 112: 1334-1338.

12. Probst $\mathbf{C}, \mathbf{N j a p a u} \mathbf{N}$ and PJ Cotty Outbreaks of an acute aflatoxicosis in Kenya in 2004: Identification of the causal agent. Applied and Environmental Microbiology 2007; 73 (8): 2762-2764.

13. Ntawuruhunga $\mathbf{P}$ and $\mathbf{J}$ Okidi Eastern Africa Root Crop Research Network (EARRNET) Legacy 2010: 56 pp.

14. Valente Soares LM and DB Rodriguez Amaya Survey of aflatoxins, chratonxin A, zealenone and sterigmatocystin in some Brazilian foods by using multi-toxin thin layer chromatography method. Journal of the Association of Official Analytical Chemists 1989; 2:22-26.

15. Bainbridge $\mathbf{Z}$, Tomlins $\mathbf{K}$, Wellings $\mathbf{K}$ and $\mathbf{A}$ Westby (eds). Methods for assessing quality characteristics of non-grain starch staples. (Part 4. Advanced Methods). Chatham, Maritime, Kent, ME4, 4TB, United Kingdom, 1996.

16. Wareing PW, Westby A, Gibbs JA, Allotey LT and M Halm Consumer preferences and fungal mycotoxin contamination of dried cassava products. International Journal of Food Science and Technology 2001; 36: 1-10.

17. VICAM. Aflatest Instruction manual. Massachusetts: VICAM, 1999.

18. CAC. Codex Alimentarius Commission. Codex general standard for contaminantsand toxins in food and feed (CODEX STAN 193-1995), 1995.

19. Muzanila YC, Brennan JG and RD King Residual cyanogens, chemical composition and aflatoxins in cassava flour from Tanzanian villages. Food Chemistry 2000; 70: 45-49.

20. Gnonlonfin GJB, Hell K, Fandohan P and AB Siame Mycoflora and natural occurrence of aflatoxins and fumonisin B1 in cassava and yam chips from Benin, West Africa. International Journal of Food Microbiology 2008; 122: 140-147.

21. Essers AJA, Ebong C, van der Grift RM, MJR Nout MJR, Otim-Nape GW and $\mathbf{H}$ Rosling Reducing cassava toxicity by heap-fermentation in Uganda. International Journal of Food Science and Nutrition 1995; 46: 125136.

22. Khonga EB Survey of fungi and mycotoxins in malts used in brewing opaque beer in Malawi. Luso: Journal of Science and Technology (Malawi) 1985; 6 (2): 49-56. 


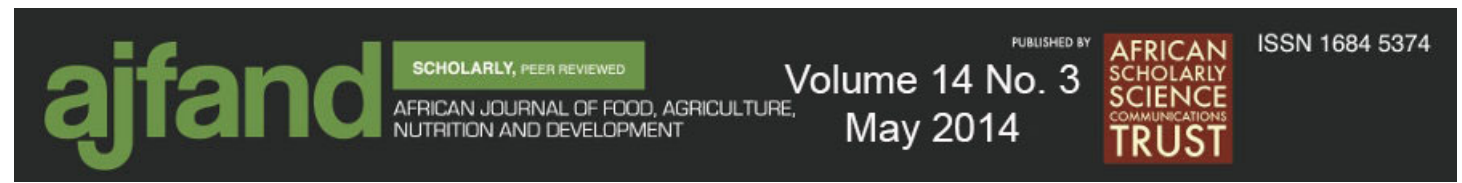

23. Kenji GM, Mvula AM, Koaze $\mathbf{H}$ and $\mathbf{N}$ Baba Aflatoxin contamination of Kenya maize flour and malted Kenyan and Malawi grains. Scientific report of the Faculty of Agriculture, Okayama University 2000; 89: 5-7.

24. Waliyar F, Siambi M, Jones R, Reedy SV, Chibonga D, Kumar PL and S Denloye Institutionalizing mycotoxin testing in Africa. In: Mycotoxin detection methods, management and public health and agricultural trade. Lessie JF, Bandyopadhayay $\mathrm{R}$ and A Visconti (Eds.). Trowbridge, UK Cromwell Press. 2008: 359-368.

25. ICRISAT (International Crops Research Institute for the Semi-Arid). Assessingoccurrence and distribution of aflatoxin in Malawi (Final project report). ICRISAT, Lilongwe, Malawi, 2010.

26. Matumba L, Monjerezi M, Khonga B and D Lakudzala Aflatoxins in traditional sorghum beer in southern Malawi. Food Control 2011; 22: 266268.

27. Wood JF Quality aspects of tradable cassava products including problems of adulteration. In: Roots, Tubers, Plantain and Bananas in animal feedings. Machin Dand S Nyrold (Eds.). FAO Animal Production and Health paper 1992; 95: 67-80.

28. Butalao-Jayme JM, Almero E, Castro MC, Jardeleza MT and LA Salama A case control dietary study of primary liver cancer risk from aflatoxins exposure. International Journal of Epidemiology 1982; 11: 112-119. 